\title{
Rescue of the fetal damage associated with high intrauterine pressure by $17 \beta$-estradiol injection in ovariectomized progesterone-treated pregnant mice
}

\author{
Daisuke Tadotsu, Noritoshi Kawate and Hiromichi Tamada
}

Department of Advanced Pathobiology, Graduate School of Life and Environmental Sciences, Osaka Prefecture University, Osaka 598-8531, Japan

\begin{abstract}
The present study examined the effects of progesterone (P) and 17ß-estradiol (E2) on fetal damage and intrauterine pressure in ovariectomized pregnant mice. The mice were ovariectomized on gestational day (GD) 9 (copulation plug = GD 0 ), and daily subcutaneous injection of various doses of P (2, 3 or $4 \mathrm{mg})$ or $4 \mathrm{mg}$ P plus E2 (0.05 or $0.1 \mu \mathrm{g})$ was given thereafter. Although P alone increased percentage of normal fetuses on GD 17 dose-dependently, fetal injury with edematous hematomata on their extremities was frequently observed. In the group treated with $4 \mathrm{mg}$ P, the injured fetus was found at the highest percentage (18\%) and intrauterine pressure was significantly higher than that in intact pregnant mice (controls). No injured fetus on GD 17 was found by the treatment with $4 \mathrm{mg}$ P plus 0.05 or $0.1 \mu \mathrm{g} \mathrm{E} 2$, and the treatments decreased the intrauterine pressure to the level of controls. Percentage of normal fetuses in the ovariectomized mice treated with $4 \mathrm{mg} P$ plus $0.05 \mu \mathrm{g}$ E2 was similar to that of controls, while that in the ovariectomized mice treated with $4 \mathrm{mg}$ P plus $0.1 \mu \mathrm{g}$ E2 markedly decreased. The results suggest that estrogen decreases intrauterine pressure to defend fetal damage in ovariectomized P-treated mice, and a high estrogen level interrupted pregnancy while keeping this estrogen action.
\end{abstract}

Key words: Estrogen, Progesterone, Fetal damage, Intrauterine pressure, Mice

ESTROGEN and progesterone (P) are required for maintaining normal pregnancy [1]. While $\mathrm{P}$ is essential for the maintenance of conceptuses, estrogen is also necessary at the time when the conceptus elongates and becomes cylindrical in rats [2]. At this stage, estrogendeficiency causes fetal damage due to high intrauterine pressure $[3,4]$ by underdevelopment of the uterine tissue framework [5-7]. Estrogen together with $\mathrm{P}$ also improves stress relaxation in the uterus by changing the state of the noncontractile elements [8]. In the rats whose uteri are distended by insertion of paraffin pellets, uterine tissue framework develops by synergistic action of estrogen and $\mathrm{P}$ [9]. Furthermore, the fetuses released into the abdominal cavity by uterine incision survive even after

Submitted Jul. 26, 2018; Accepted Aug. 28, 2018 as EJ18-0302 Released online in J-STAGE as advance publication Sep. 19, 2018 Correspondence to: Hiromichi Tamada, D.V.M., Ph.D., Department of Advanced Pathobiology, Graduate School of Life and Environmental Sciences, Osaka Prefecture University, 1-58 Rinku Ourai Kita, Izumisano-shi, Osaka 598-8531, Japan.

E-mail:tamada@vet.osakafu-u.ac.jp ovariectomy and/or treatment with anti-P RU 486 in late pregnant rats, indicating that indispensable actions of ovarian hormones for fetal survival are directed to the physical properties of uteri in late pregnancy $[10,11]$. Namely, well-known action of $P$ for inhibition of uterine smooth muscle activity through its receptor signaling [12] and enlargement of uterine tissue framework for rapidly growing fetuses by $\mathrm{P}$ plus estrogen could be critical for maintenance of late pregnancy. However, since the latter theory has been introduced by the experiments using rats, it is unknown whether the theory could be suitable for other species. Mice is one of the other representative experimental mammals in which uterine genes induced by estrogen does not tolerably correspond with those in rats [13], and deficiency of $\mathrm{P}$ and/or estrogen is easily induced by ovariectomy during pregnancy [14, 15]. Especially in mid pregnancy of the mouse, $P$ alone could not maintain pregnancy unless present in very high amounts while the presence of estrogen lowered the P requirements within the physiological range [15]. Here, the present study examined the effects of $\mathrm{P}$ and $17 \beta-$ 
estradiol (E2) on fetal damage and intrauterine pressure in ovariectomized pregnant mice.

\section{Materials and Methods}

\section{Animals}

Adult ICR male and female mice ( 8 weeks old) were purchased from Japan SLC (Hamamatsu, Japan). Mice were maintained at a regulated room temperature (24 $\pm 1^{\circ} \mathrm{C}$ ) and with lighting from 0500 to $1900 \mathrm{~h}$. Animals were given a commercial diet (CE-2; Clea, Osaka, Japan) and water ad libitum. Females were mated overnight with males at proestrus, and the day when a copulation plug was found was designated GD 0. Bilateral ovariectomy, laparotomy for observing fetal states and determination of intrauterine pressure were performed under anesthesia by i.p. injection of $40 \mathrm{mg} / \mathrm{kg}$ sodium pentobarbital (Somnopentyl; Kyoritsu Seiyaku, Tokyo, Japan) between 1100 and $1400 \mathrm{~h}$, and animals were euthanized by overdose of sodium pentobarbital. The study was performed in accordance with the Guidelines for Animal Experimentation of Osaka Prefecture University, Japan and was approved by the Animal Experiment Committee of Osaka Prefecture University (approval number: 21$68)$.

\section{Determination of intrauterine pressure}

The intrauterine pressure was determined for two to five allantoic cavities per mouse using pressure transducer (Nihon Kohden, Tokyo, Japan) immediately after laparotomy under anesthesia. The uterine wall, containing a live fetus, was picked with a $20 \mathrm{G}$ needle connected to the transducer through a polyethylene tube and the needle was placed in the allantoic cavity. To minimize the effect of the leakage of allantoic fluid through the needle prick on the next determination, the fetuses not contiguous to the already determined ones were chosen for the following determinations. The signal from the transducer was amplified and recorded by a pen recorder. Pressure determination in each conceptus was completed within $2 \mathrm{~min}$. The average value of the base-line pressures between small uterine contractions was calculated for each mother.

\section{Classification of conceptuses}

The numbers of live normal, injured, and absorbing fetuses were recorded. Live normal fetuses were defined as those being alive without visible signs of injury; injured fetuses were defined as live fetuses bearing edematous hematomata; absorbing fetuses were those which were in the process of absorption including traces of implantation sites. The average weights of the live fetuses and their placentae were determined for each litter.

\section{Experimental design}

Female mice were ovariectomized on GD 9, and subcutaneous injection with $\mathrm{P}$ alone or with $\mathrm{E} 2$ was given immediately after the operation and daily at $1400 \mathrm{~h}$ thereafter until the day before sacrifice. The steroids were dissolved in $0.1 \mathrm{~mL}$ sesame oil. The dosages of $\mathrm{P}$ and E2 were chosen with reference to the study by Miller [14]. Determination of intrauterine pressure, classification of fetuses or conceptuses and measurement of fetal and placental weights were performed at specified days of gestation.

Experiment 1 was carried out to examine the effects of different doses of $\mathrm{P}$ on the rate of classified fetuses. Ovariectomized mice were injected with $0,2,3$ or $4 \mathrm{mg}$ $\mathrm{P}$ and examined on GD 17. Intact pregnant mice were used as controls. Intrauterine pressure was determined in ovariectomized mice treated with $4 \mathrm{mg} \mathrm{P}$ and controls.

Experiment 2 examined the changes in the rate of classified fetuses and intrauterine pressure on GDs 15 and 16 in the ovariectomized mice treated with $4 \mathrm{mg}$ P.

Experiment 3 was performed to examine the effects of different doses of $\mathrm{E} 2$ on the rate of classified fetuses and intrauterine pressure in the ovariectomized mice treated with $4 \mathrm{mg}$ P. Ovariectomized mice were treated with 4 mg P together with 0.05 or $0.1 \mu \mathrm{g}$ E2 and examined on GD 17.

\section{Statistical analyses}

The fetal and placental weight and intrauterine pressure are expressed as the mean $( \pm$ standard error of the mean). The values were compared between groups by Student's $t$-test or Scheffe's F test. The occurrence of the classified fetuses was expressed as a percentage of the total number of conceptuses, and a comparison between groups was done by $\chi^{2}$ analysis of $2 \times 2$ contingency tables or Fisher's exact probability test, followed by Bonferroni correction. In Experiment 1, the values of controls were compared with those in the other groups. The values in Experiment 2 were compared with those in the ovariectomized mice treated with $4 \mathrm{mg} \mathrm{P}$ in Experiment 1. The values in Experiment 3 were compared with those in controls of Experiment 1. Values of $p<0.05$ were considered statistically significant. 


\section{Results}

Table 1 shows the rates of classified fetuses, fetal and placental weights and intrauterine pressure in Experiments 1, 2 and 3. In intact controls of Experiment 1, nearly all conceptuses were maintained normally, but 2 fetuses in one mouse had hematomata on their face or clunis without edema. Ovariectomy on GD 9 completely obstructed pregnancy, and conceptuses were all absorbed or expelled (OVX group). Daily injection with P after ovariectomy improved maintenance of pregnancy in a dose-dependent manner, and treatment with $4 \mathrm{mg} \mathrm{P}$ maintained $43.1 \%$ of conceptuses normally. However, 10 out of 13 mice in this P-treated group (OVX $+4 \mathrm{mg} \mathrm{P})$ had injured fetuses bearing hematomata on their extremities as shown in Fig. 1. Many injured fetuses had hematomata with edema and/or physical constriction on the head, waist or clunis. Totally, $18.0 \%$ of conceptuses was classified as injured fetuses. Fetal and placental weights in the ovariectomized P-treated groups were not different from those in intact controls. Intrauterine pressure in ovariectomized mice treated with $4 \mathrm{mg} \mathrm{P}$ was significantly higher than that in intact controls.

In ovariectomized pregnant mice treated with $4 \mathrm{mg} \mathrm{P}$, the rate of normal fetuses on GD 15 or 16 (Experiment 2) was significantly greater than that on GD 17 in Experiment 1. On the other hand, injured fetuses were not found on GD 15, and 3 out of 6 mice on GD 16 had one or 2 injured fetuses. The rate of injured fetuses against total number of conceptuses in this group was $7.5 \%$. Intrauterine pressure on GD 15 was similar to that on GD 16, and these values were significantly lower than that on GD 17 (ovariectomized mice treated with $4 \mathrm{mg} \mathrm{P}$ in Experiment 1). The results indicate that intrauterine pressure in ovariectomized mice treated with $4 \mathrm{mg} \mathrm{P}$ increased from GD 16 to GD 17.

All of the ovariectomized pregnant mice treated with 4 $\mathrm{mg}$ P plus $0.05 \mu \mathrm{g}$ E2 had normal fetuses, and $91.2 \%$ of total number of conceptuses was classified as normal fetuses (Experiment 3). The weights of live fetuses and their placentae were not different from those in intact controls in Experiment 1. On the other hand, only 8 out of 15 ovariectomized mice treated with $4 \mathrm{mg} P$ plus 0.1 $\mu \mathrm{g}$ E2 had normal fetuses, and $33.6 \%$ of conceptuses was classified as normal fetuses. The weights of live fetuses and their placentae were significantly smaller than those in intact controls in Experiment 1. Intrauterine pressures in ovariectomized pregnant mice treated with $4 \mathrm{mg} P$ plus 0.05 or $0.1 \mu \mathrm{g}$ E2 were not different from that in intact controls in Experiment 1.

\section{Discussion}

Hosoda and Ichikawa [16] showed that the intrauterine pressure in pregnant rats decreases during late pregnancy regardless of the rapid growth of conceptuses. The

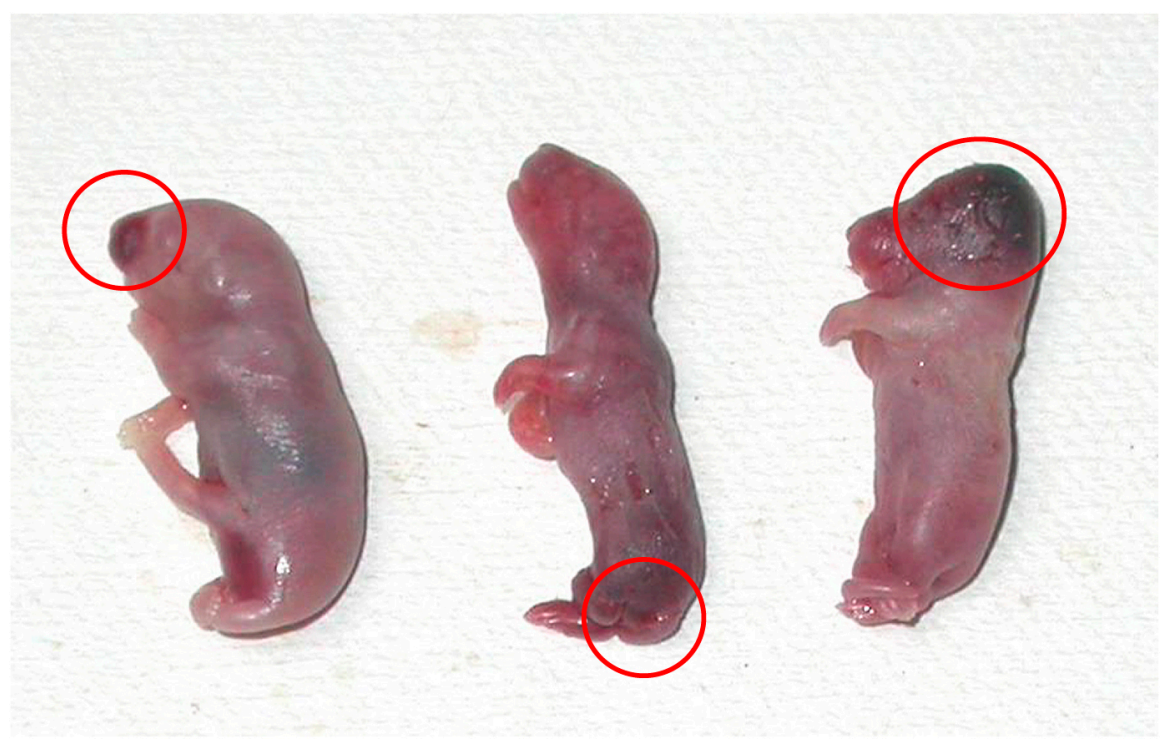

Fig. 1 Injured fetuses on GD 17 in P-treated ovariectomized mice. From left to right: a fetus bearing a hematoma on the face around the mouth; a fetus with a constricted waist and a slight edematous hematoma on the clunis; a fetus with an edematous hematoma on the head. Red circles indicate the sites of hematomata. 


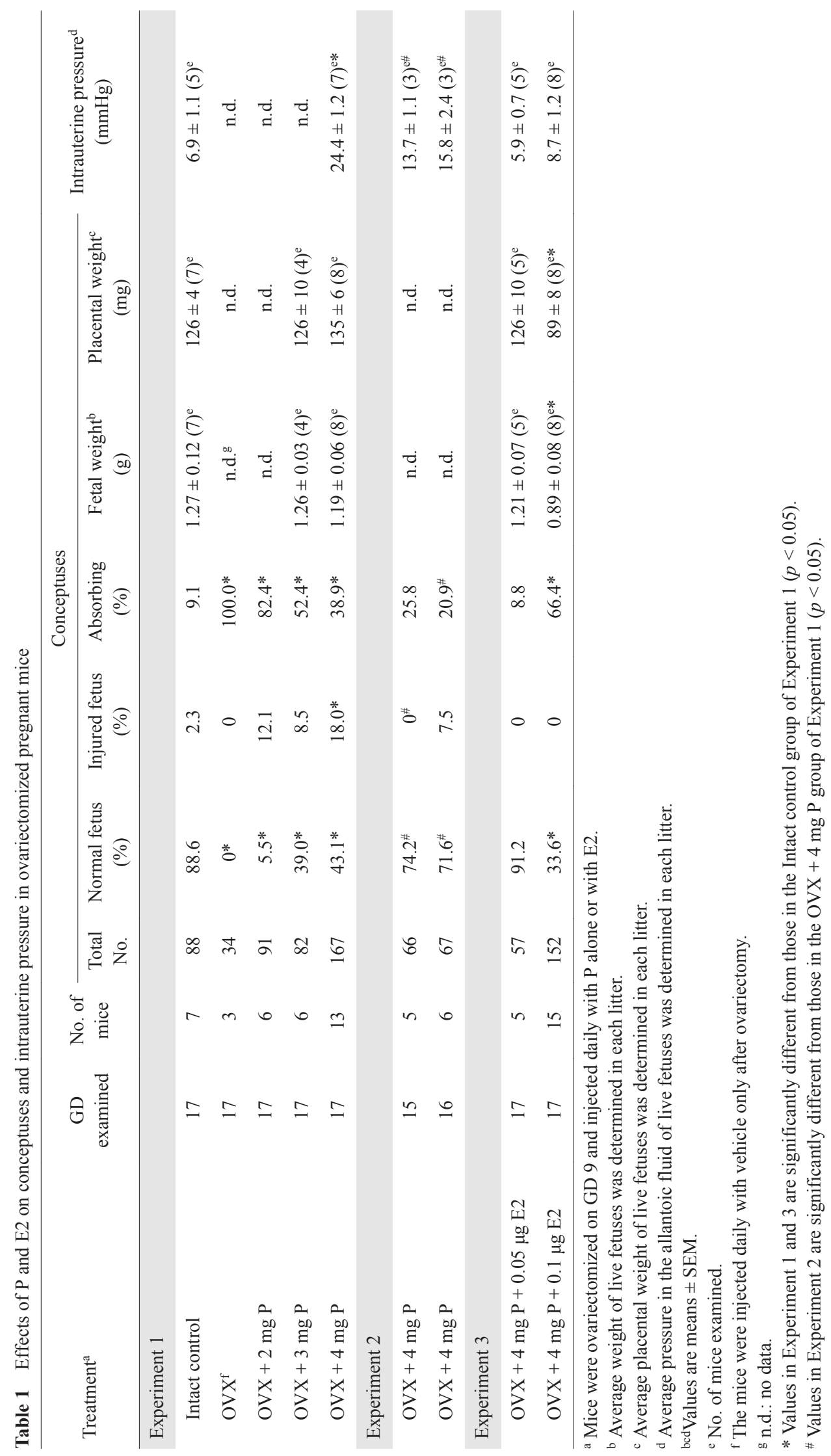


present study examined whether estrogen deficiency causes fetal damage by high intrauterine pressure in mice. Estrogen deficiency is induced by ovariectomy and supplementation with $\mathrm{P}$ only in pregnant mice $[14,15]$. In the rats ovariectomized on GD 13 (sperm present $=$ GD 0 ) and daily treated with $4 \mathrm{mg}$ P, injured fetuses appeared very frequently from GD 17 [2] under high intrauterine pressure $[3,4]$. Similarly in mice, the results of Experiment 1 showed that ovariectomy on GD 9 with following daily injection of $4 \mathrm{mg} P$ induces fetal damage associated with high intrauterine pressure. Lower doses of $\mathrm{P}$ induced absorbing fetuses at the rate of more than a half and did not fully maintain pregnancy itself. Although it is unclear why two fetuses in one mouse had hematomata in intact controls, it may be possible that the abdomen of the mouse accidentally suffered from some physical force to cause a fetal bruise.

The results of Experiment 2 showed that fetal injury occurs from GD 15 through GD 17 in the ovariectomized mice treated with $4 \mathrm{mg}$ P. Especially from GD 16 through GD 17, the rate of injured fetuses increased from $7.5 \%$ to $18.0 \%$, and average intrauterine pressure showed 1.5 -fold increase. The results support the idea that increased intrauterine pressure is related to the occurrence of fetal injury.

In the ovariectomized mice treated with $4 \mathrm{mg} P$ plus $0.05 \mu \mathrm{g}$ E2 in Experiment 3, fetuses were normally maintained, and intrauterine pressure was not different from that in intact pregnant mice on GD 17. The results together with those in Experiment 1 suggest that estrogen deficiency causes fetal injury associated with high intra- uterine pressure. These findings support our idea that $\mathrm{P}$ plus estrogen enlarge uterine tissue framework for rapidly growing fetuses in late pregnancy, which was introduced by the experiments using rats [5-7, 9]. This critical role by steroid hormones for maintenance of late pregnancy may be applied to not only rats but also mice. On the other hand, in the ovariectomized mice treated with 4 $\mathrm{mg}$ P plus $0.1 \mu \mathrm{g}$ E2, the rate of absorbing conceptuses were $66.4 \%$, while intrauterine pressure was not different from that in intact pregnant mice. In this group, the weights of live fetuses and their placentas were also significantly decreased when compared to those in intact pregnant mice. The same effect of E2 was reported in the mice ovariectomized on GD 10 and treated with $5 \mathrm{mg} \mathrm{P}$ [14]. The results of the present study suggest that a high estrogen level may interrupt pregnancy while keeping the effect of estrogen to lower intrauterine pressure. Although the reason why the high dose of E2 deteriorated placental and fetal growth is not clear, it has been reported that estrogen inhibits trophoblast maturation and development of fetal blood vessels in placentas and induces coagulative necrosis in decidua basalis [17].

In conclusion, the results of the present study suggest that estrogen decreases intrauterine pressure in late pregnancy to defend fetal damage in ovariectomized Ptreated mice, and that a high estrogen level interrupted pregnancy while keeping this estrogen action.

\section{Acknowledgements}

The authors thank Dr. K Kida for her valuable advice.

\section{References}

1. Courrier R (1950) Interaction between estrogen and progesterone. Vitam Horm 8: 179-214.

2. Tamada H, Ichikawa S (1980) The effect of estrogen on fetal survival in progesterone-treated ovariectomized rats. Endocrinol Japon 27: 163-167.

3. Ichikawa S, Tamada H (1980) The effect of oestrogen on uterine plasticity in late pregnant rats. $J$ Reprod Fert 58: 165-168.

4. Tamada H, Nakamura H, Mori J (1989) Maintenance of low intrauterine pressure by estrogen and progesterone during late pregnancy in rats. Jpn J Anim Reprod 35: 193197.

5. Tamada H, Yagasaki O, Ichikawa S (1984) The effect of estrogen on passive length-tension relationship in the uterus of ovariectomized progesterone-treated pregnant rats.
Int J Fertil 29: 239-243.

6. Tamada H, Ohtani H, Mori J (1990) The effect of estrogen and progesterone on the volume-pressure curve of the uterine ampulla in late pregnant rats. Endocrinol Japon 37: 943-947.

7. Tamada H, Shimizu $Y$, Inaba $T$, Kawate N, Sawada $T$ (2004) The effects of the aromatase inhibitor fadrozole hydrochloride on fetuses and uteri in late pregnant rats. $J$ Endocrinol 180: 337-345.

8. Tamada H, Ichikawa S (1983) The effect of ovarian hormones on stress relaxation in the uterus of the pregnant rat. Endocrinol Japon 30: 537-542.

9. Tamada H (1985) Synergistic effect of estrogen and progesterone on the physical properties of the chronically distended rat uterus. Jpn J Anim Reprod 31: 211-215 (in 
Japanese).

10. Tamada H, Mori J (1995) Fetal survival in ovariectomized uterus-incised rats. Lab Anim Sci 45: 281-284.

11. Tamada H, Inaba T, Sawada T (1998) A progesterone antagonist cannot prevent fetal survival if the uterine horn is incised. Endocr J 45: 785-789.

12. Wu SP, DeMayo FJ (2017) Progesterone receptor signaling in uterine myometrial physiology and preterm birth. Curr Top Dev Biol 125: 171-190.

13. Kwekel JC, Forgacs AL, Williams KJ, Zacharewski TR (2013) O-p'-DDT-mediated uterotrophy and gene expression in immature C57BL/6 mice and Sprague-Dawley rats. Toxicol Appl Pharmacol 273: 532-541.
14. Miller BG (1978) Effects of ovarian hormones on foetal and placental growth in the mouse. Aust J Biol Sci 31: 641-648.

15. Milligan SR, Finn CA (1997) Minimal progesterone support required for the maintenance of pregnancy in mice. Hum Reprod 12: 602-607.

16. Hosoda K, Ichikawa S (1984) Changes of intrauterine pressure in progesterone-treated ovariectomized rats during the second half of pregnancy. Nihon Naibunpi Gakkai Zasshi 60: 846-851 (in Japanese).

17. Scott JN, Adejokun F (1980) Placental changes due to administration of diethylstilbestrol (DES). Virchows Arch B Cell Pathol Incl Mol Pathol 34: 261-267. 